\title{
SELEÇÃO DE GENÓTIPOS DE ACEROLEIRA ASSISTIDA POR MARCADORES ISOENZIMÁTICOS VISANDO À RESISTÊNCIA A Meloidogyne incognita RAÇA $2^{1}$
}

\author{
JACKELINE GADÉ DE ARAUJO ROSSITER ${ }^{2}$, ROSIMAR DOS SANTOS MUSSER ${ }^{3}$, LUIZA SUELY SEMEN MARTINS ${ }^{4}$, \\ ELVIRAMARIAREGIS PEDROSA ${ }^{5}$, JEANE EMILLI DE MEDEIROS ${ }^{6}$
}

RESUMO-A cultura da aceroleira despertou um grande interesse do mercado consumidor, tendo em vista o alto teor de vitamina C (ácido ascórbico), que varia entre 1.325 a $2.250 \mathrm{mg}$ por $100 \mathrm{~mL}$ de suco. Com a expansão da cultura, surgiram problemas fitossanitários, entre os quais a infecção das raízes da aceroleira por nematóides. Os produtos químicos utilizados no controle dos nematóides são agressivos ao meio ambiente, e a seleção de genótipos resistentes e tolerantes constitui-se na melhor alternativa para a solução do problema. O trabalho foi desenvolvido em casa de vegetação com 18 genótipos de aceroleira, com o objetivo de encontrar genótipos resistentes e tolerantes a Meloidogyne incognita raça 2 assistida por marcadores isoenzimáticos, para indicar plantas destinadas a porta-enxerto. A avaliação foi realizada 60 dias após a inoculação mediante análise das variáveis: número de ovos por planta e por grama de raiz, índice de galhas e massa de ovos, biomassa fresca relativa do sistema radicular e biomassa fresca relativa da parte aérea. Os resultados permitiram identificar o genótipo 023-CMF como menos suscetível, e os genótipos 027-CMF e 035-CMF, como mais suscetíveis. Estudos realizados através da eletroforese isoenzimática com os sistemas $\alpha$ esterase, fosfatase ácida e peroxidase, 20; 40 e 60 dias após a inoculação com ovos de $M$. incognita raça 2, possibilitaram relacionar a expressão de proteínas com a suscetibilidade. Os genótipos mais próximos geneticamente, com índice de similaridade 0,941, foram 027-CMF e 026-CMF, 046-CMF e 026-CMF, e 041CMF e 026-CMF. O menor índice de similaridade genética $(0,115)$ foi observado entre os genótipos 002-SPE e 036-CMF.

Termos para indexação: porta-enxerto, nematóide, isoenzimas.

\section{GENOTYPE SELECTION OF BARBADOS CHERRY USING ISO-ENZYMATIC MARKERS FOR RESISTANCE TO Meloidogyne incognita race2}

\begin{abstract}
The culture of the Barbados cherry has increased great interest in the consuming market, in view of high levels of vitamin C, each $100 \mathrm{ml}$ of juice has contents of $1,325 \mathrm{mg} / 2,250 \mathrm{mg}$ of vitamin C (Ascorbic acid). With the increase of the plantations phytosanitary problems appeared, such as infection of the roots for nematodes. The utilisation of chemical products for controlling nematodes is unsafe for the environment, therefore the election of resistant and tolerant genotypes is the best solution for this problem. The work was developed in greenhouse, with eighteen genotypes of Barbados cherry aiming to find resistant genotypes to Meloidogyne incognita race 2, marked with iso-enzymatic markers, indicating plants destined for rootstock. Sixty days after the inoculation, the evaluation of the variables began: amount of eggs per plant and weight of root, index of galls and eggs mass, fresh biomass relative to the root systems, fresh biomass relative to the aerial part. The results permitted to identify the genotype 023-CMF as the less susceptible and the genotypes 027-CMF and 035-CMF as the most susceptible. Studies carried out through iso-enzymatic electrophoresis with the systems $\alpha$-esterase, acid phosphatase and peroxidase. Twenty, forty and sixty days after the inoculation with eggs of $M$. incognita race2, made it possible to relate the expression of proteins with the susceptibility. The genotypes genetically closer, with index of similarity 0.941 are: 027-CMF and 026-CMF, 046-CMF and 026-CMF and 041-CMF and 026-CMF. The lesser indices of genetic similarity 0.115 are: genotypes 002-SPE and 036-CMF.
\end{abstract}

Index terms: rootstock, nematode, isoenzymes.

\section{INTRODUÇÃO}

A cultura da aceroleira (Malpighia emarginata D. C.) despertou grande interesse dos produtores e do mercado consumidor em razão do alto teor de vitaminas e compostos benéficos do fruto, como antioxidantes, detectados na década de 40 por Asenjo (1959). Os carotenóides presentes na acerola podem fornecer 720 a 4.540 unidades internacionais de vitamina A por 100 gramas de fruto, enquanto a concentração de vitamina $\mathrm{C}$ pode variar entre 1.325 e $2.250 \mathrm{mg}$ por $100 \mathrm{~mL}$ de suco (Assis et al., 2001).

Com o desenvolvimento e expansão da cultura da aceroleira no Brasil, a utilização dos porta-enxertos resistentes e tolerantes a patógenos habitantes de solo tornou-se uma necessidade. Em levantamentos realizados em áreas produtoras

\footnotetext{
${ }^{1}$ (Trabalho 268-07). Recebido em: 12-11-2007. Aceito para publicação em: 17-07-2008.

${ }^{2}$ Mestranda em Melhoramento Genético de Plantas.

${ }^{3}$ Departamento de Agronomia.

${ }^{4}$ Departamento de Biologia.

${ }^{5}$ Departamento de Tecnologia Rural.

${ }^{6}$ Mestranda em Fitopatologia - Universidade Federal Rural de Pernambuco, CEP 52.171-900, Dois Irmãos, Recife-PE; e-mail: jgarossiter@gmail.com.br
} 
no Brasil, foi identificado como principal problema da aceroleira, os nematóides do gênero Meloidogyne. Neste gênero, foram identificadas as espécies $M$. incognita raças $1 ; 2 ; 3$ e 4, $M$. javanica e M. arenaria raça 2 (Ferraz et al., 1989).

O nematóide das galhas é um fitopatógeno que causa danos de importância econômica (International Board Plant Genetic Resourges, 1986), e sua infestação prejudica a absorção de água e nutrientes, gerando sintomas de enfraquecimento na parte aérea e sistema radicular (Choudhury \& Choudhurdy, 1992). A diagnose é facilmente realizada por meio de análise do solo e raízes, e os danos podem ser confundidos com outros problemas de ordem fisiológica, a exemplo de deficiência nutricional, estresse hídrico, pela ocorrência de pragas e outras doenças (Ritzinger \& Ritzinger, 2005). Nas raízes, os sintomas caracterizam-se por engrossamentos, galhas e os sinais pela presença de massas de ovos (Ritzinger \& Ritzinger, 2005).

A interação planta-patógeno envolve mecanismos bioquímicos, onde os genes de alerta de defesa da planta são ativados, resultando na síntese de novos compostos e no aumento da atividade enzimática (Moraes, 1998). Estudos isoenzimáticos são utilizados em casos de estresse biótico ou abiótico por estarem relacionados ao entendimento das mudanças metabólicas e mecanismos de defesa desencadeados nas plantas (Torggler et al., 1995).

A técnica de eletroforese com isoenzimas, que é definida como diferentes formas moleculares de uma mesma enzima, que ocorrem num mesmo organismo, com afinidade por um mesmo substrato, fornece um meio de avaliação da variação genética (Ferreira \& Grattapaglia, 1998). Essa técnica é considerada de custo baixo e de ótimos resultados, sendo que os polimorfismos enzimáticos estão mais próximos da expressão fenotípica final do que os polimorfismos de DNA, por serem um produto intermediário da expressão do gene (Torggler et al., 1995).

Marcadores isoenzimaticos têm sido utilizados para avaliar alterações enzimáticas em plantas parasitadas por nematóides em vários patossistemas, estando esterase, fosfatase ácida e peroxidase entre as isoenzimas mais estudadas (Assis, 2006).

O objetivo deste trabalho foi iniciar a busca em 18 genótipos de acerolado Banco Ativo de Germoplasma pertencente a UFRPE, quanto à resistência e tolerância a $M$. incognita raça 2 assistida por marcadores isoenzimáticos com a atividade das isoenzimas esterase, fosfatase ácida e peroxidase, para indicar plantas destinadas a porta-enxerto, visando, num futuro próximo, à melhoria na produção de mudas comerciais.

\section{MATERIAL E MÉTODOS}

O experimento foi conduzido no Departamento de Agronomia da sede da UFRPE, onde foram testados 18 genótipos de aceroleira, sendo 17 do Banco Ativo de Germoplasma da Universidade Federal Rural de Pernambuco (UFRPE) e uma matriz independente (Tabela 1).

Estacas semilenhosas foram coletadas entre o $8^{\circ}$ e o $10^{\circ}$ nó, apresentando dois pares de folhas e dois internódios (Musser, 2001). As estacas foram mantidas em estufa para a emissão do sistema radicular por 58 dias em substrato (areia lavada, carvão vegetal e esterco de galinha, na proporção 10:1:1 v/v). Posteriormente, as estacas foram transplantadas para sacos de polietileno de $20 \times 25 \mathrm{~cm}$, com capacidade para dois quilos, contendo substrato comercial e solo fumigado com brometo de metila $(3: 1 \mathrm{v} / \mathrm{v})$.

\section{Avaliação dos genótipos quanto à resistência e tolerância} ao nematóide

O inóculo foi preparado a partir de raízes de tomateiro infectadas por $M$. incognita, raça 2. Para tal, as raízes foram cuidadosamente retiradas do substrato, lavadas em água corrente e cortadas em pequenos fragmentos, seguindo-se a extração de ovos conforme a técnica descrita por Hussey \& Barker (1973). Em seguida, a suspensão foi imediatamente passada em peneiras de 200 e 500 Meshes, tipo "US Standard Series". Os ovos retidos na peneira de 500 Meshes foram lavados em água corrente para a remoção dos resíduos de hipoclorito de sódio e transferidos, com a ajuda de uma pipeta, para um Becker de $100 \mathrm{~mL}$. Dessa suspensão, retiraram-se amostras para a contagem dos ovos em caixas calibradas. A concentração da suspensão foi ajustada para 2.000 ovos $/ \mathrm{mL}$.

A inoculação dos nematóides foi realizada após 60 dias do plantio, através da disposição de 18.000 ovos por planta, colocados em três pequenas depressões de $2 \mathrm{~cm}$ de profundidade ao redor do colo da planta. Os tratamentos foram representados pelos genótipos, sendo repetidos quatro vezes. As plantas receberam regas diárias. A técnica adotada foi a mesma da obtenção do inóculo (Hussey \& Barker, 1973). Dessa suspensão, retiraramse alíquotas para a contagem dos ovos em caixas calibradas.

Os parâmetros avaliados após 60 dias da infecção dos genótipos em relação ao parasitismo por $M$. incognita foram: exame do sistema radicular, avaliando o índice de galhas (IG) e índice de massa de ovos (IMO) através da escala de notas do International Meloidogyne Project (IMP), utilizada por Taylor \& Sasser (1978). As reações dos hospedeiros foram enquadradas nos parâmetros estabelecidos por Sasser (1980). O delineamento utilizado foi o inteiramente casualizado, em arranjo fatorial de $18 \mathrm{x}$ 2, correspondendo a 17 genótipos e uma matriz independente, e dois tratamentos de inoculação (com ou sem infestação de $M$. incognita) e quatro repetições. Cada parcela era formada por uma planta. Para avaliar a reprodução do nematóide, foram estimados o número de ovos por sistema radicular (OSR) e o número de ovos por grama de raiz (OGR). Paralelamente, foram determinadas a biomassa fresca relativa da parte aérea (BFRPA) e a biomassa fresca relativa do sistema radicular (BFRSR), através da relação $B F R P A=B F P A / B F P A N I$ e BFRSR=BFSRI/BFSRNI. Os dados foram submetidos à análise de variância, e as médias, separadas pelo teste de Tukey, ao nível de 5\% de probabilidade. Os dados de BFRPA e BFRSR foram transformados em $\sqrt{(\mathrm{X}+1)}$ antes da análise, enquanto os dados de IMO, OSR e OGR foram transformados para $\log _{10}(\mathrm{x}+1)$.

\section{Análises isoenzimáticas}

As análises isoenzimáticas foram conduzidas no Laboratório de Genética, do Departamento de Biologia da UFRPE, quando se retiraram 3 folhas em cada coleta, realizada a $0 ; 20 ; 40$ 
e 60 dias após a infestação.

Para a extração das enzimas, foi usado $0,3 \mathrm{~g}$ de folhas previamente lavadas em água corrente, e o excesso de água, retirado com papel toalha. Durante o processo de extração, as amostras permaneceram à baixa temperatura para evitar a desnaturação de proteínas e, conseqüentemente, a perda da atividade enzimática. A trituração foi manual, em almofariz de porcelana, com auxílio de nitrogênio líquido. Ao material macerado, foram adicionados $2,5 \mathrm{~mL}$ de solução extratora [sacarose $(0,2 \mathrm{M}) 2$ g; PVP-40 (2,56\%) 2 g; EDTA (5\%) 1 g; 2-mercaptoetanol (0,2\%) 1 mL e tampão A (1,2 g hidróxido de lítio, 11,89 g ácido bórico e $1.000 \mathrm{~mL}$ de água destilada) e Tampão B (1,6 g ácido cítrico $(0,008 \mathrm{M}), 6,6 \mathrm{~g}$ Tris $(0,05 \mathrm{M})$ e $1.000 \mathrm{~mL}$ de água destilada) $2,5 \mathrm{~mL}$ (1 mL:9 mL)]. A adição de sacarose e 2-mercaptanol teve por finalidade proteger as enzimas contra efeitos de metabólicos secundários liberados pela ruptura dos tecidos (Scandalios, 1969). As amostras foram centrifugadas a $4.000 \mathrm{xg}$ por $5 \mathrm{~min}$ a $4{ }^{\circ} \mathrm{C}$. Alíquotas de $10 \mu \mathrm{L}$ de cada amostra foram aplicadas aos poços dos géis. Os géis de poliacrilamida a 7\% AA/BIS (acrilamida e bisacrilamida-solução-estoque a 30\%) foram preparados com a homogeneização de $17 \mathrm{~mL}$ da solução-estoque de acrilamida e bis-acrilamida em $7 \mathrm{~mL}$ de tampão borato de lítio $0,2 \mathrm{M}, \mathrm{pH} 8,3$ e 67 $\mathrm{mL}$ de tampão tris-citrato $0,2 \mathrm{M}, \mathrm{pH} 8,3$. À mistura, foram adicionados $75 \mu \mathrm{L}$ de TEMED (tetrametildiamina) e $0,75 \mathrm{~mL}$ de persulfato de amônia a $18 \%$. Em seguida, a mistura foi vertida no molde de vidro até a polimerização completa e colocada numa cuba horizontal contendo tampão borato de lítio $0,2 \mathrm{M}$, fazendose uso de tecido perfex como ponte de conexão.

A migração eletroforética foi conduzida a $4^{\circ} \mathrm{C}$, a um potencial de $40 \mathrm{~V}$, até que a linha de fronte atingisse $7,0 \mathrm{~cm}$ em direção ao pólo positivo, marcada com azul de Bromofenol. Para a resolução dos sistemas enzimáticos, adotaram-se os procedimentos baseados na metodologia proposta por Scandalios (1969) e/ou Alfenas (1998), com algumas modificações.

Para revelação de $\alpha$-esterase ( $\alpha$-EST), os géis foram corados, usando-se $3,0 \mathrm{~mL}$ de $\alpha$-naftil acetato $1 \%$, em acetona 50\%; $40 \mathrm{mg}$ de fast blue RR salt; $50 \mathrm{~mL}$ de tampão fosfato de sódio monobásico $0,2 \mathrm{M} ; \mathrm{pH} 4,2 ; 10 \mathrm{~mL}$ de tampão fosfato de sódio dibásico 0,2 M; pH 9,2; e $40 \mathrm{~mL}$ de água destilada, sendo em seguida incubados por 2 horas, no escuro, a $30^{\circ} \mathrm{C}$. Para a revelação de fosfatase ácida (ACP), fez-se uso de $100 \mathrm{mg}$ de $\alpha$ naftil fosfato ácido de sódio; $100 \mathrm{mg}$ de fast garnet GBC salt; $1 \mathrm{~mL}$ de $\mathrm{MgCl}_{2}$ a $1 \%$; e $100 \mathrm{~mL}$ de tampão acetato de sódio $0,2 \mathrm{M} ; \mathrm{pH}$ 5,0 . Em seguida, os géis foram incubados a $30^{\circ} \mathrm{C}$ por 2 horas. $\mathrm{O}$ sistema peroxidase (PO) foi revelado usado-se $0,065 \mathrm{~g}$ de 3 -amino-

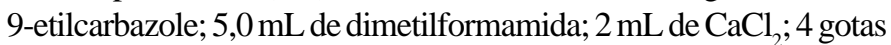
de $\mathrm{H}_{2} \mathrm{O}_{2}$ a 30\%; e $85 \mathrm{~mL}$ de tampão acetato de sódio $0,05 \mathrm{M} ; \mathrm{pH}$ 5,0 . A coloração ocorreu no escuro à temperatura de $30^{\circ} \mathrm{C}$, por 2 horas. Nas cubas, para as corridas eletroforéticas, foi utilizado tampão borato de lítio $0,2 \mathrm{M}$; pH 8,3 para as três enzimas estudadas. Todos os géis, após a coloração, foram lavados, fixados (em solução contendo álcool metílico, ácido acético e água destilada na proporção de $1: 1: 1 \mathrm{v} / \mathrm{v}$ ) por 20 minutos, avaliados para a confecção dos zimogramas e, em seguida, fotografados.

A interpretação dos zimogramas foi realizada através da identificação de bandas em loci gênicos relacionados com o parasitismo. Os genótipos foram analisados usando-se o coeficiente de Nei \& Li (1979), através do programa NTSYS- pc (Numerical Taxonomy and Multivariater Analysis System, versão 1.70, Exeter software, NY, USA) e a árvore filogenética gerada usando-se a opção UPGMA (Unweighted Pair - Group Method, Aritmetic Average).

\section{RESULTADOS E DISCUSSÃO}

Na avaliação da relação do parasitismo do nematóide $M$. incognita raça 2, para as variáveis BFRPA e BFRSR (Tabela 1), não foi verificado diferença significativa, possivelmente devido aos altos coeficientes de variação, mostrando assim que esse parâmetro de avaliação não foi decisivo para a escolha de material, geneticamente resistente a $M$. incognita raça 2. Esses resultados confirmam os obtidos por Gomes et al. (2000), trabalhando com aceroleira e M. javanica.

De maneira geral, os genótipos não diferiram em relação ao IG, IMO, OSR e OGR (Tabela 1), exceto o genótipo 018-CMF, que apresentou IG $<3$, diferindo significativamente dos genótipos 005-APE, 025-CMF, 027-CMF e 041-CMF. O genótipo 023-CMF apresentou OSR significativamente menor do que 027-CMF e 035-CMF, sem diferir dos demais.

Com relação à resposta enzimática para os três sistemas estudados: á-esterase ( $\alpha$-EST), fosfatase ácida (ACP) e peroxidase (PO), observou-se um total de oito regiões de bandas polimórficas que foram identificadas e analisadas: cinco bandas para o sistema $\alpha$-esterase; uma banda para o sistema fosfatase ácida, e duas bandas para o sistema peroxidase. De acordo com Scandalios (1969), o sistema isoenzimático de esterase é constituído por um complexo e heterogêneo grupo de enzimas reativas com uma ampla gama de substratos específicos, sendo as variantes destas proteínas encontradas em plantas, geralmente monoméricas ou diméricas (Weeden \& Wendel, 1990), com alto nível de variabilidade (Gillespie \& Langley, 1974), constituindose um dos sistemas enzimáticos mais polimórficos. A classificação das esterases é feita de acordo com suas afinidades para a naftil acetato, sua mobilidade em gel de acrilamida ou amido e sua seqüência de nucleotídeos (Hemingway \& Karunaratne, 1998).

Para o sistema $\alpha$-esterase (Figura 1), foram observados cinco regiões de bandas anódicas, designadas $\alpha$-Est- $1, \alpha$-Est-2, $\alpha$-Est-3, $\alpha$-Est-4 e $\alpha$-Est-5. Nos genótipos 001-SPE, 002-SPE e 003-APE, foram reveladas as regiões $\alpha$-Est-3 e $\alpha$-Est- 4 em todos os tratamentos, variando apenas na intensidade das mesmas aos 40 dias após a infecção, as quais apresentaram-se mais intensas.

Nas testemunhas, os genótipos 005-APE, 007-TPA, 015CPA, 025-CMF, 026-CMF, 027-CMF, 035-CMF, 036-CMF, 041-CMF e a Matriz-PPE apresentaram as bandas $\alpha$-Est-2 e $\alpha$-Est-5; o genótipo 018-CMF apresentou a banda $\alpha$-Est-5; o genótipo 023CMF não revelou nenhuma banda; o genótipo 024-CM

F revelou as bandas $\alpha$-Est-2 e $\alpha$-Est- 4 , e os genótipo 036CMF e 046-CMF revelaram as bandas $\alpha$-Est-1, $\alpha$-Est-2 e $\alpha$-Est-5.

Aos 20 dias de infestação do solo com o nematóide, nos genótipos 005-APE, 015-CPA, 018-CMF, 025-CMF, 036-CMF e a Matriz-PPE, foi revelada apenas a banda $\alpha$-Est- 5 e nos 
genótipos 024-CMF e 033-CMF apenas a $\alpha$-Est-2. Para os demais genótipos, foram detectadas as bandas $\alpha$-Est- 2 e $\alpha$-Est- 4 . Nas amostras coletadas aos 40 dias, os genótipos 001-SPE, 002-SPE e 003-APE revelaram as bandas $\alpha$-Est-3 e $\alpha$-Est-4, e os demais genótipos revelaram as bandas $\alpha$-Est-2 e $\alpha$-Est-5.

Nas coletas efetuadas aos 60 dias, nos genótipos 005APE, 018-CMF, 023-CMF, 026-CMF, 041-CMF, 046-CMF e a Matriz-PPE, foram reveladas as bandas $\alpha$-Est-2 e $\alpha$-Est-5; nos genótipos 015-CPA e 025-CMF, observou-se somente a banda $\alpha$-Est-5; no genótipo 007-TPA e 035-CMF, foram reveladas as bandas $\alpha$-Est- $1, \alpha$-Est-2 e $\alpha$-Est-5, no 024-CMF, as bandas $\alpha$ Est-2, $\alpha$-Est-4 e $\alpha$-Est-5; no 024-CMF e 027-CMF, as bandas $\alpha$ Est-2, $\alpha$-Est-4 e $\alpha$-Est-5; no 035-CMF, as bandas $\alpha$-Est-1, $\alpha$-Est2 e $\alpha$-Est-5, e no 036-CMF, as bandas $\alpha$-Est-4 e $\alpha$-Est-5.

Os resultados observados por Gomes et al. (2004) confirmaram expressão de respostas de esterase em plantas de bananeira com estresse salino de cinco locos semelhante aos obtidos. Estudos realizados com citros revelaram expressão de esterase de apenas três locos, sendo menor do que os demais sistemas estudados (Oliveira \& Radmann, 2005). A esterase é uma enzima envolvida em reações de hidrólise de ésteres, estando diretamente ligada ao metabolismo dos lipídios como os fosfolipídios totais de membrana (Santos et al., 2005).

A enzima fosfatase ácida (Figura 2) tem função de hidrolisar os fosfomonoésteres de um grande número de reações químicas vegetais, entre as quais a formação de sacarose durante a fotossíntese (Tanksley, 1983). Essa enzima apresentou apenas uma região de banda (Acp-1), a qual não foi ativada nos genótipos 015-CPA, 036-CMF e na Matriz-PPE das testemunhas. Aos 20 dias, com a presença do patógeno, os genótipos 015-CPA e 036CMF mostraram bandas que voltaram a ter atividade, e os genótipos 001-SPE e 002-SPE não demonstraram atividade. Aos 40 dias, o genótipo 002-SPE voltou a ter atividade, e o 024-CMF, 025-CMF e 036-CMF não revelaram a Acp-1. Aos 60 dias, todos os genótipos revelaram a banda em questão. Este número de alelos expressos é inferior ao encontrado por outros autores, como Gomes et al. (2004), com três alelos, e Malone et al. (2006), com três e quatro alelos, ao estudarem padrões isoenzimáticos de fosfatase ácida em banana e arroz, respectivamente. Estudos realizados com plantas de alpínia, parasitadas por M. incognita, revelaram alta expressão de fosfatase ácida, que diferiu acentuadamente de plantas não-parasitadas (Assis, 2006). A fosfatase ácida é considerada um excelente marcador devido a sua atividade para genes de resistência em plantas (Zhong et al., 1999); no entanto, a participação dessa enzima na patogênese ou resposta da planta à infecção não está clara (Assis, 2006).

A peroxidase tem importante função metabólica na regulação iônica, ajuste osmótico e produção de NADPH, participa da fotorrespiração e atua na fixação de $\mathrm{CO}_{2}$, sendo cada função dependente da localização da enzima dentro da planta (mitocôndrias, peroxissomas ou cloroplastos) (Alfenas, 1998). A atividade dessa enzima (Figura 3) nas plantas-controle só revelou uma região de banda (Po1), entretanto sem atividade para os genótipos 001-SPE, 002-SPE, 003-APE, 005-APE, 007-TPAe 018CMF. Nas coletas efetuadas aos 20 dias após a infestação do solo, os genótipos 001-SPE, 005-APE, 023-CMF, 035-CMF e a
Matriz-PPE apresentaram atividade das bandas Po1 e Po2, os genótipos 002-SPE e 015-CPA revelaram a banda Po2 e os demais mostraram atividade da banda Po1.

Aos 40 dias de exposição ao solo infestado nos genótipos 001-SPE, 002-SPE, 007-TPA, 023-CMF, 035-CMFe 041CMF foram reveladas as bandas Po1 e Po2, nos genótipos 005APE, 015-CPA, e a Matriz-PPE identificou-se à banda Po2 e nos demais à banda Po1. Aos sessenta dias de exposição, a presença do patógeno levou a ativação das bandas Po1 e Po2 nos genótipos 001-SPE, 007-TPA e 035-CMF, enquanto nos genótipos 002-SPE, 005-APE e 015-CPA somente a banda Po2 foi detectada, e nos demais genótipos, apenas a banda Po1.

Em estudos conduzidos por Lopes et al. (2002), foram expressos dois locos para peroxidase, quando avaliava a estimativa da taxa de cruzamento em aceroleiras. Mellon (1991) relata que alterações nos níveis de peroxidase e distribuição de isoformas são conhecidas por acompanhar processos de mecanismos de defesa dos hospedeiros a patógenos, como lignificação e suberização.

Quanto ao comportamento dos três sistemas isoenzimáticos estudados frente a resposta da planta à presença do patógeno, e considerando o genótipo 023-CMF como o menos suscetível, constatou-se que, no sistema esterase, a presença do patógeno ativou as bandas $\alpha$-Est- 2 e $\alpha$-Est- 5 que não estavam presente na testemunha. No sistema peroxidase, a presença do patógeno ativou a região de banda Po2, mas a mesma não foi ativa aos 60 dias após a inoculação no sistema fosfatase ácida, não sendo possível relacionar as bandas reveladas com a resposta da planta ao patógeno.

$\mathrm{Na}$ análise de agrupamento (Figura 4), foi observada a distribuição dos 18 genótipos em grupos de maior e menor proximidade genética. De acordo com o dendrograma, os genes expressos pelas isoenzimas analisadas permitiram separar os genótipos em dois grandes grupos. $\mathrm{O}$ primeiro formado pelos genótipos 001-SPE, 002-SPE, 003-APE, 005-APE, 015-CPA e a Matriz-PPE, e o segundo, formado pelos demais genótipos. No segundo grupo, encontram-se, em subgrupos diferentes, o genótipo 023-CMF, considerado o menos suscetível, e os genótipos 027-CMF e 035-CMF, identificados como os mais suscetíveis, segundo a quantidade de ovos por sistema radicular (OSR).

Os índices de similaridade genética entre os genótipos expressos pela percentagem de variantes idêntica em cada par comparado, em relação ao número total encontrado, são mostrados na Tabela 2. O menor índice de similaridade genética $(0,115)$ foi observado entre os genótipos 002-SPE e 036-CMF. Os genótipos mais próximos geneticamente, com índice de similaridade 0,941, foram 027-CMF e 026-CMF, 046-CMF e 026CMF, e 041-CMF e 026-CMF.

As diferentes respostas dos genótipos, expressas pela presença do patógeno, identificadas por avaliações morfológicas, fisiológicas e moleculares, mostraram que, mesmo pertencentes a mesma espécie botânica, apresentam alta variabilidade genética, ao ponto de possibilitar a indicação de genótipos resistentes a nematóides para futuros trabalhos de melhoramento genético da aceroleira. 
TABELA 1 - Biomassa fresca relativa da parte aérea (BFRPA), biomassa fresca relativa do sistema radicular (BFRSR), índice de galhas (IG), índice de massa de ovos (IMO), índice de ovos por sistema radicular (OSR) e ovos por grama de raiz (OGR) de 18 genótipos de aceroleira inoculados com $M$. incognita raça 2, após 60 dias da infestação.

\begin{tabular}{|c|c|c|c|c|c|c|c|}
\hline GENÓTIPO & BFRPA & BFRSR & IG & IMO & OSR & & OGR \\
\hline 001-SPE (1) & $0,83 \mathrm{a}^{*}$ & $0,90 \mathrm{a}$ & $4,00 \mathrm{ab}$ & $2,63 \mathrm{a}$ & 11185,95 & $a b$ & $1386,96 \mathrm{a}$ \\
\hline 002-SPE (2) & $1,33 \mathrm{a}$ & $2,00 \mathrm{a}$ & $3,93 \mathrm{ab}$ & $3,31 \mathrm{a}$ & 16788,80 & $a b$ & $2665,44 \mathrm{a}$ \\
\hline 003-APE (3) & $0,89 \mathrm{a}$ & $1,67 \mathrm{a}$ & $4,65 a b$ & $3,93 \mathrm{a}$ & 22156,35 & $a b$ & $1397,55 \mathrm{a}$ \\
\hline 005-APE (5) & $2,92 \mathrm{a}$ & $5,17 \mathrm{a}$ & $5,00 \mathrm{a}$ & $4,65 \mathrm{a}$ & 41718,49 & $a b$ & 7458,67 a \\
\hline 007-TPA (7) & $1,50 \mathrm{a}$ & $1,66 \mathrm{a}$ & $4,48 \mathrm{ab}$ & $3,24 \mathrm{a}$ & 17055,38 & $a b$ & $2180,57 \mathrm{a}$ \\
\hline 015-CPA (15) & $0,75 \mathrm{a}$ & $0,60 \mathrm{a}$ & $4,00 \mathrm{ab}$ & $2,46 \mathrm{a}$ & 3377,12 & $a b$ & 3377,12 a \\
\hline 018-CMF (18) & $1,33 \mathrm{a}$ & $0,90 \mathrm{a}$ & $2,91 \quad \mathrm{~b}$ & $2,30 \mathrm{a}$ & 3198,37 & $a b$ & $602,17 \mathrm{a}$ \\
\hline 023-CMF (23) & $1,25 \mathrm{a}$ & $1,03 \mathrm{a}$ & $4,23 \mathrm{ab}$ & $2,72 \mathrm{a}$ & 2596,36 & b & $653,30 \mathrm{a}$ \\
\hline 024-CMF (24) & $2,94 \mathrm{a}$ & $2,00 \mathrm{a}$ & $4,65 a b$ & $3,31 \mathrm{a}$ & 6129,55 & $a b$ & $613,47 \mathrm{a}$ \\
\hline 025-CMF (25) & $1,19 \mathrm{a}$ & $2,11 \mathrm{a}$ & $5,00 \mathrm{a}$ & $3,93 \mathrm{a}$ & 28636,32 & $a b$ & $3151,85 \mathrm{a}$ \\
\hline 026-CMF (26) & $1,50 \mathrm{a}$ & $1,33 \mathrm{a}$ & $4,00 \mathrm{ab}$ & $2,46 \mathrm{a}$ & 5291,37 & $a b$ & $748,50 \mathrm{a}$ \\
\hline 027-CMF (27) & $1,10 \mathrm{a}$ & $1,37 \mathrm{a}$ & $5,00 \mathrm{a}$ & $3,95 \mathrm{a}$ & 65647,52 & a & $5503,71 \mathrm{a}$ \\
\hline 033-CMF (33) & $4,92 \mathrm{a}$ & $1,40 \mathrm{a}$ & $3,47 \mathrm{ab}$ & $3,00 \mathrm{a}$ & 6413,68 & $a b$ & $1015,50 \mathrm{a}$ \\
\hline 035-CMF (35) & $1,22 \mathrm{a}$ & 0,96 a & $4,48 \mathrm{ab}$ & $3,90 \mathrm{a}$ & 78183,88 & $\mathrm{a}$ & $11057,70 \mathrm{a}$ \\
\hline 036-CMF (36) & $1,27 \mathrm{a}$ & $1,58 \mathrm{a}$ & $4,48 \mathrm{ab}$ & $3,95 \mathrm{a}$ & 10350,43 & $a b$ & $1322,72 \mathrm{a}$ \\
\hline 041-CMF (41) & $0,89 \mathrm{a}$ & $0,58 \mathrm{a}$ & $4,73 \mathrm{a}$ & $3,40 \mathrm{a}$ & 5961,19 & $a b$ & $1002,64 \mathrm{a}$ \\
\hline 046-CMF (46) & $2,50 \mathrm{a}$ & $1,50 \mathrm{a}$ & $3,90 \mathrm{ab}$ & $2,46 \mathrm{a}$ & 17204,15 & $a b$ & 2433,09 a \\
\hline Matriz-PPE (M) & $0,38 \mathrm{a}$ & $1,44 \mathrm{a}$ & $4,31 \mathrm{ab}$ & $4,00 \mathrm{a}$ & 50424,37 & $\mathrm{ab}$ & $6992,65 \mathrm{a}$ \\
\hline CV\% & 0,10 & 1,42 & 7,19 & $\overline{3,83}$ & 11,56 & & 16,09 \\
\hline
\end{tabular}

* Médias seguidas da mesma letra em cada coluna não diferem significativamente, ao nível de 5\% de probabilidade, pelo teste de Tukey. Os dados BFRPA e BFRSR foram transformados em $\sqrt{(\mathrm{X}+1})$, sendo apresentados os dados originais. Os dados IMO, OSR e OGR foram transformados em log ${ }_{10}(\mathrm{x}+1)$, sendo apresentados os ant $\log$ dos dados originais.

TABELA 2 - Similaridade genética observada entre 18 genótipos de aceroleira obtidas pela expressão das isoenzimas $\alpha$-esterase, fosfatase ácida e peroxidase, após 60 dias da infestação.

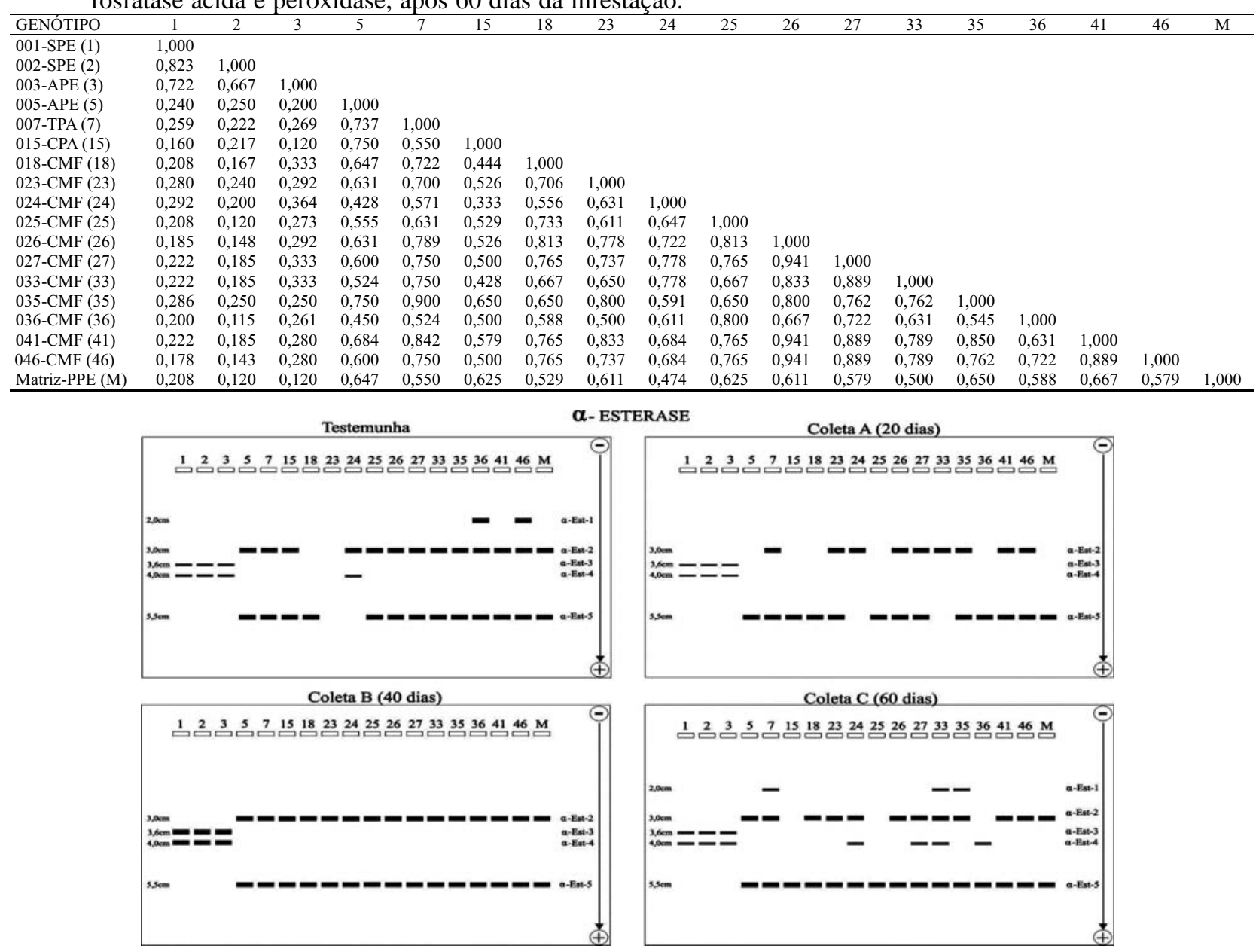

FIGURA 1 - Zimograma da isoenzima $\alpha$-esterase de 18 genótipos de aceroleira [001-SPE(1); 002-SPE(2); 003-APE(3); 005-APE(5); 007TPA(7); 015-CPA(15); 018-CMF(18); 023-CMF(23); 024-CMF(24); 025-CMF(25); 026-CMF(26); 027-CMF(27); $033-$ CMF(33); 035-CMF(35); 036-CMF(36); 041-CMF(41); 046-CMF(46) e Matriz-PPE(M)] parasitados por Meloidogyne incognita raça 2, nos períodos de coleta A (20 dias), coleta B (40 dias) e coleta C (60 dias), após a infestação do solo. 


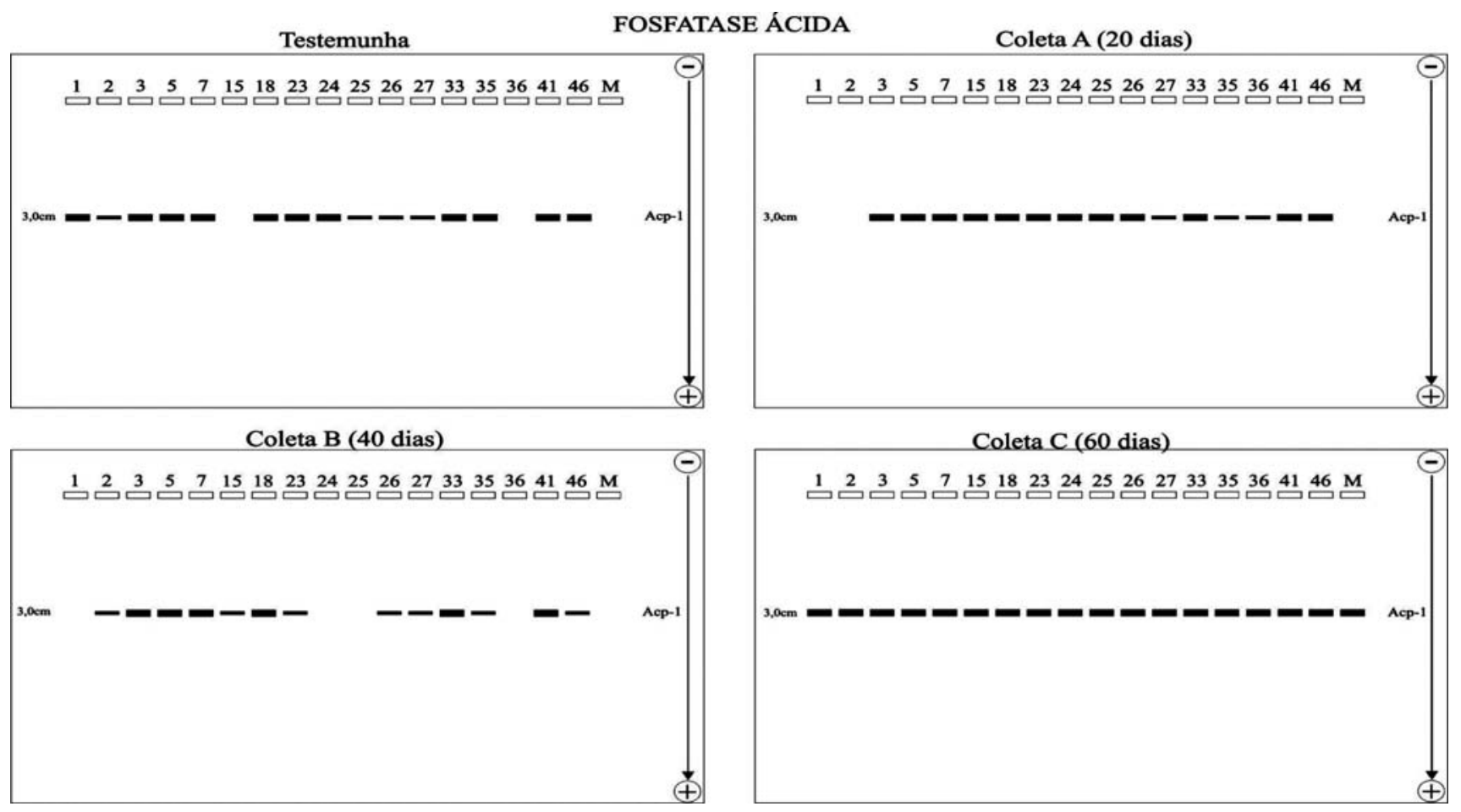

FIGURA 2 - Zimograma da isoenzima fosfatase ácida de 18 genótipos de aceroleira [001-SPE(1); 002-SPE(2); 003-APE(3); 005-APE(5); 007-TPA(7); 015-CPA(15); 018-CMF(18); 023-CMF(23); 024-CMF(24); 025-CMF(25); 026-CMF(26); 027-CMF(27); 033-CMF(33); 035CMF(35); 036-CMF(36); 041-CMF(41); 046-CMF(46) e Matriz-PPE(M)] parasitados por Meloidogyne incognita raça 2, nos períodos de coleta A (20 dias), coleta B (40 dias) e coleta C (60 dias), após a infestação do solo.

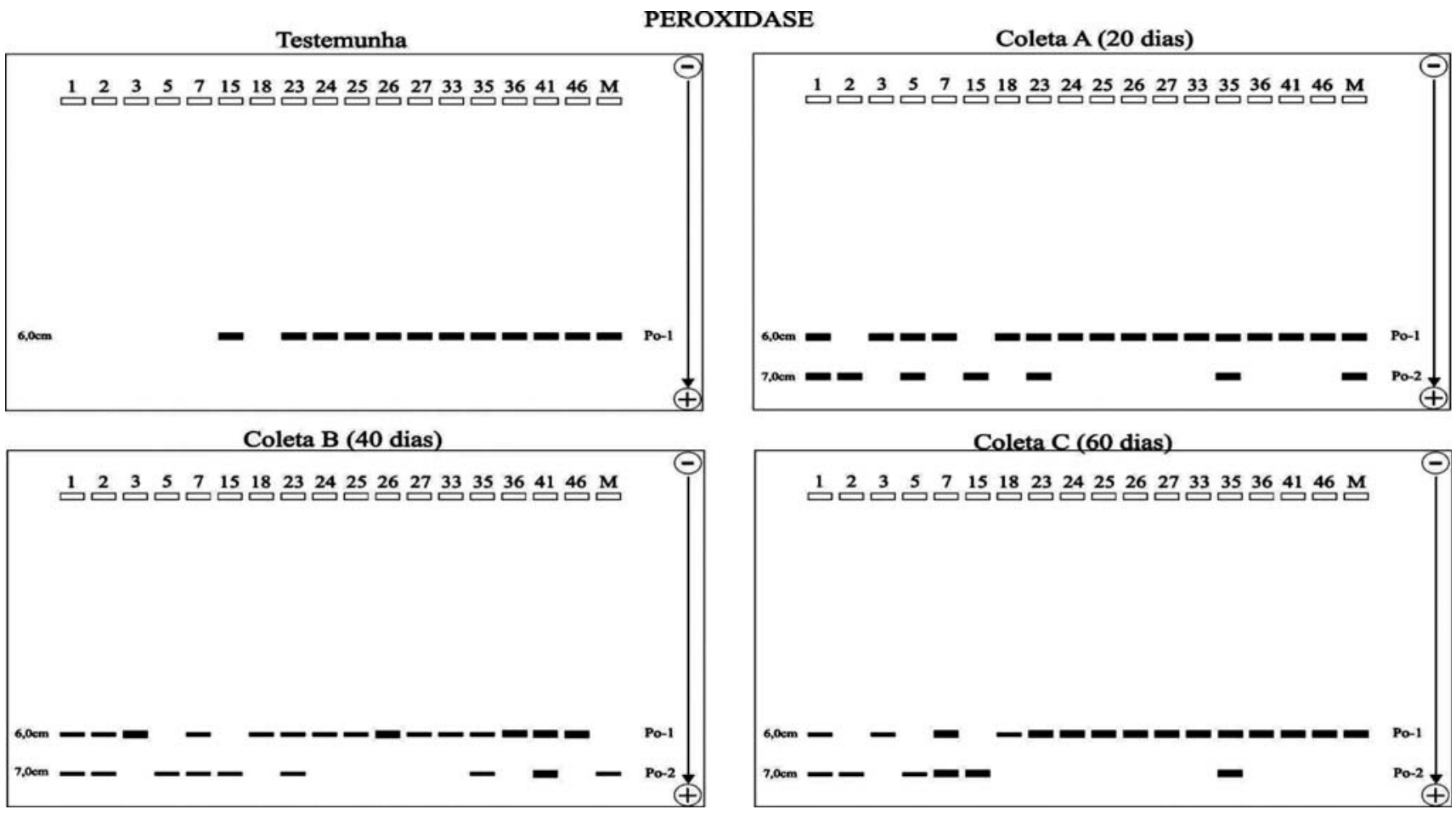

FIGURA 3 - Zimograma da isoenzima peroxidase de 18 genótipos de aceroleira [001-SPE(1); 002-SPE(2); 003-APE(3); 005-APE(5); 007TPA(7); 015-CPA(15); 018-CMF(18); 023-CMF(23); 024-CMF(24); 025-CMF(25); 026-CMF(26); 027-CMF(27); $033-$ $\mathrm{CMF}(33)$; 035-CMF(35); 036-CMF(36); 041-CMF(41); 046-CMF(46) e Matriz-PPE(M)] parasitados por Meloidogyne incognita raça 2, nos períodos de coleta A (20 dias), coleta B (40 dias) e coleta C (60 dias), após a infestação do solo. 


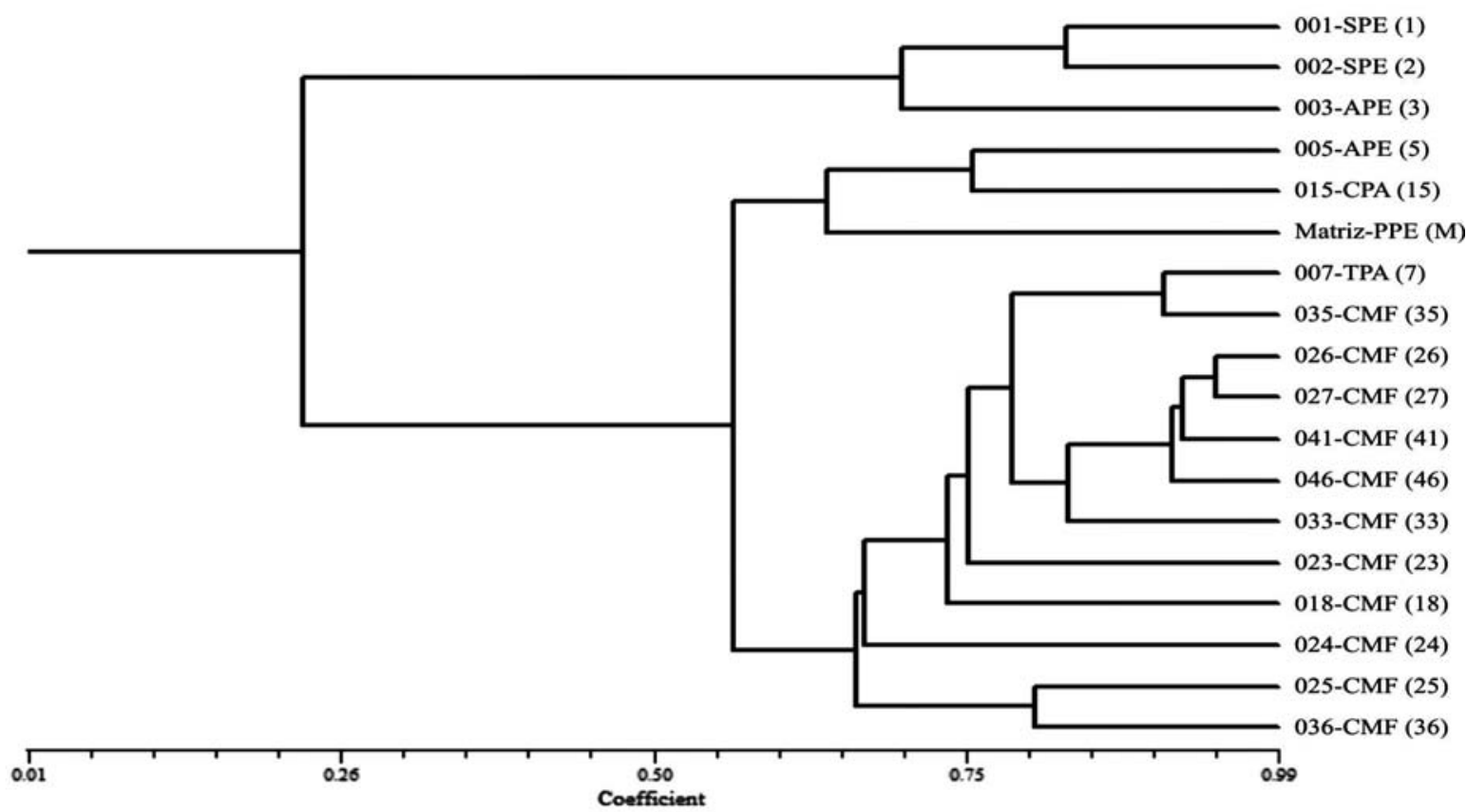

FIGURA 4 - Dendrograma de 18 genótipos de aceroleira, construído a partir dos produtos da revelação das isoenzimas $\alpha$-esterase, fosfatase ácida e peroxidase, usando o método de agrupamentos UPGMA.

\section{CONCLUSÃO}

1-Na análise da biomassa fresca relativa da parte área e do sistema radicular, não foi encontrado diferença significativa, provavelmente devido o estudo ter sido feito em apenas um ciclo de reprodução do nematóide.

2-O genótipo 023-CMF destacou-se como o mais tolerante à infecção por ovos do nematóide, podendo assim ser recomendado aos produtores de acerola.

\section{AGRADECIMENTOS}

À CAPES, pela concessão da bolsa ao primeiro autor, ao Programa de Educação Tutorial (PET/MEC/SESu) e à UFRPE, através do Programa de Pós-Graduação em Melhoramento Genético de Plantas e pela disponibilidade das equipes e dos Laboratórios de Fitonematologia e de Genética.

\section{REFERÊNCIAS}

ALFENAS, A. C. (Ed.). Eletroforeses de isoenzimas e proteínas afins: fundamentos e aplicações em plantas e microrganismos. Viçosa: UFV, 1998.574 p.

ASENJO, C. F. Aspectos químicos y nutritivos de la acerola (Malpighia punicifolia L.). Ciência, México, v. 19, n 6-7, p. 109$118,1959$.
ASSIS, S. A.; LIMA, D. C.; OLIVEIRA, O. M. M. F. Activity of pectinmethylesterase, pectin content and vitamin $\mathrm{C}$ in acerola fruit at stages of fruit development, Food Chemistry, London, v. 74,p. 133-137, 2001.

ASSIS, T.C. Fitonematóides associados a Zingiberales ornamentais em Pernambuco, determinação do número de amostras, efeito de indutores de resistência e avaliação de mecanismos envolvidos. 2006. 105 f. Tese (Doutorado) Universidade Federal Rural de Pernambuco, Recife, 2006.

CHOUDHURY, M. M.; CHOUDHURY, E.N. Ocorrência de nematóides das galhas em aceroleira irrigada no Submédio São Francisco. Petrolina-PE: EMBRAPA-CPATSA, 1992. 2p. (Comunicado Técnico, 50).

FERRAZ, L. C.C. B.; MONTEIRO, R. R.; INOMOTO, M. M. Hospedabilidade da acerola em relação a sete espécies de fitonematóides. Nematologia Brasileira, Piracicaba, v. 13, p. 3949, 1989.

FERREIRA, M. E.; GRATTAPAGLIA, D. Introdução ao uso de marcadores moleculares em análise genética. 3. ed. Brasília: EMBRAPA/Cenargen. 1998. 220 p.

GILLESPE, J. H.; LANGLEY, C. H. A general model to account for enzyme variation in natural populations. Genetics, Bethesda, v.76, p.837-887, 1974 .

GOMES, E. W. F.; WILLADINO, L.; MARTINS, L, S. S.; SILVA, S. O.; CÂMARA, T. R. Diplóides (AA) de bananeira submetidos 
ao estresse salino. Pesquisa Agropecuária Brasileira, Brasília, v. 39, p. 525-531, 2004.

GOMES, E.; DILERMANDO, P.; MARTINS, A. B. G.; FERRAUDO, A. S. Análise de grupamentos e de componentes principais no processo seletivo em genótipos de aceroleira (Malpighia emarginata), Revista Brasileira de Fruticultura, Jaboticabal, v. 22, n. 1, p. 36-39, 2000.

HEMINGWAY, J.; KARUNARATNE, S. H. P. P. Mosquito carboxylesterases: A review $f$ the molecular biology and biochemistry of a major insecticide resistance mechanism. Medical and Veterinary Entomology, Oxford, v. 12, p. 1-12, 1998.

HUSSEY, R. S.; BARKER, K. R. A comparison of methods of collecting inocula of Meloidogyne spp., including a new technique. Plant Disease Reporter, St. Paul, v. 57, p. 1025-1028, 1973.

INTERNATIONAL BOARD PLANT GENETIC RESOURCES. Malpighia emarginata: acerola. In: INTERNATIONAL BOARD PLANT GENETIC RESOURCES. Genetic resources of tropical and subtropical fruits and nuts (excluding musa). Rome, 1986. p. 52-54.

LOPES, R.; BRUCKNER, C. H.; LOPES, M. T. G. Estimação da taxa de cruzamento da aceroleira com base em dados isoenzimáticos. Revista Agropecuária Brasileira, Brasília, v. 37 , n. 3, p. 321-327. 2002.

MALONE, G.; ZIMMER, P. D.; CASTRO, A. S.; CARVALHO, I. L.; MENEGHELLO, G. E.; PESKE, S. T. Identificação do estádio adequado para realização de análises isoenzimáticas em arroz. Revista Brasileira de Sementes, Brasília, v. 28, p.193-200. 2006.

MELLON, J. E. Purification and characterization of isoperoxidases elicited by Aspergillus flavus in cotton ovule cultures. Plant Physiology, New York, v. 95, p. 14-20, 1991.

MORAES, M. G. Mecanismos da resistência sistêmica adquirida em plantas. Revisão Anual de Patologia de Plantas, Passo Fundo, v. 6, p. 261-284, 1998.

MUSSER, R. S. Caracterização de acessos de aceroleira (Malpighia emarginata) do Banco Ativo de Germoplasma da UFRPE em Pernambuco. 2001. 143 f. Tese (Doutorado)Universidade Federal Rural de Pernambuco, Recife, 2001.
NEI, M.; LI, W. H. Mathematical model for studying genetic variation in terms of restriction endonucleases. Proceeding of the National Academy of Sciences of the United States of America, Washington, v.76, p.5269-5273, 1979.

OLIVEIRA, R. P.; RADMANN, E. B. Genetic similarity of citrus freh fruit market cultivars. Revista Brasileira de Fruticultura, Jaboticabal, v. 27, n. 2, p. 332-334, 2005.

RITZINGER, C. H.; RITZINGER, R. Nematóides em acerola. Cruz das Almas: Embrapa Mandioca e Fruticultura, 2005. Disponível em: <http://www.boletimpecuario.com.br/ artigos >. Acesso em: 23 mar. 2007.

SANTOS, C. M. R.; MENEZES, N. L.; VILELLA, F. A. Modificações fisiológicas e bioquímicas em sementes de feijão no armazenamento. Revista Brasileira de Sementes, Pelotas, v. 27, p. 104-114. 2005.

SASSER, J. N. Root-knot nematodes; a global menace to crop production. Plant Disease, St Paul, v. 64, p. 36-41, 1980.

SCANDALIOS, J. G. Genetic control multiple molecular forms of enzymes in plants: a review Biochemical Genetics, New York, v. 3, p. 37-39, 1969.

TANKSLEY, S. D. Isozymes. Amsterdam: Elsevier, 1983. part B, $472 \mathrm{p}$.

TAYLOR, A. L.; SASSER, J. N. Biology identification and control of root-knot nematodes (Meloidogyne species). Raleigh: North Carolina State University Graphics, 1978. 111p.

TORGGLER, M. G. F.; CONTEL, E. P. B.; TORGGLER, S. P. Isoenzimas: variabilidade genética em plantas. Ribeirão Preto: Sociedade Brasileira de Genética, 1995, 175p.

WEEDEN, N. F.; WENDEL, J. F. Genetics of plant isozymes.In: SOLTIS, D.E.; SOLTIS, P.S. (Ed.). Isozymes in plant biology. London: Champman and Hall, 1990. p. 46-72.

ZHONG, X. B.; BODEAU, J.; FRANSZ, P. F.; WILLIAMSON, V. M.; VAN KAMMEN, A.; JONG, J. H.; ZABEL, P. FISH to meiotic pachytene chromossome of tomato locates the root-knot nematode resistance gene Mi- 1 and the acid phosphatase gene Aps-1 near the junction of euchromatin and pericentromeric heterochromatin of chromossome arms $6 \mathrm{~S}$ and $6 \mathrm{~L}$, respectively. Theoretical and Applied Genetics, Berlin, v. 98, p. 365-370, 1999. 